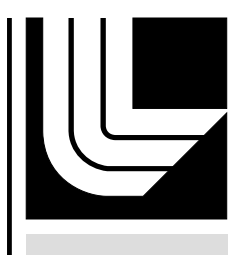

LAW RENCE LIVERMORE N A TIO N A L LABORATORY

Beam Dump Design for the Rare Isotope Accelerator Fragmentation Line

W. Stein, L. E. Ahle, S. Reyes

May 5, 2006 
This document was prepared as an account of work sponsored by an agency of the United States Government. Neither the United States Government nor the University of California nor any of their employees, makes any warranty, express or implied, or assumes any legal liability or responsibility for the accuracy, completeness, or usefulness of any information, apparatus, product, or process disclosed, or represents that its use would not infringe privately owned rights. Reference herein to any specific commercial product, process, or service by trade name, trademark, manufacturer, or otherwise, does not necessarily constitute or imply its endorsement, recommendation, or favoring by the United States Government or the University of California. The views and opinions of authors expressed herein do not necessarily state or reflect those of the United States Government or the University of California, and shall not be used for advertising or product endorsement purposes.

This work was performed under the auspices of the U.S. Department of Energy by University of California, Lawrence Livermore National Laboratory under Contract W-7405-Eng-48. 
UCRL-XXXXXX

\title{
Beam Dump Design for the Rare Isotope Accelerator Fragmentation Line*
}

\author{
Werner Stein** \\ Larry E. Ahle** \\ Susana Reyes**
}

May 1, 2005

**Lawrence Livermore National Laboratory, Livermore, California

*Work performed under the auspices of the U.S. Department of Energy by the University of California Lawrence Livermore National Laboratory under Contract W7405-Eng-48. 


\title{
Beam Dump Design for the Rare Isotope Accelerator Fragmentation Line
}

\author{
Werner Stein \\ Larry E. Ahle \\ Susana Reyes
}

\begin{abstract}
Beam dumps for the heavy ion beams of the fragmentation line of the Rare Isotope Accelerator have been designed. The most severe operational case involves a continuous U beam impacting the beam dump with a power of $295 \mathrm{~kW}$ and a nominal spot diameter size of $5 \mathrm{~cm}$. The dump mechanically consists of two rotating barrels with a water cooled outer wall of $2 \mathrm{~mm}$ thick aluminum. The barrels are $70 \mathrm{~cm}$ in diameter and axially long enough to intercept a variety of other beams. The aluminum wall absorbs approximately $15 \%$ of the U beam power with the rest absorbed in the water downstream of the wall. The water acts as an absorber of the beam and as a coolant for the $2 \mathrm{~mm}$ aluminum wall. The barrel rotates at less than 400 RPM, maximum aluminum temperatures are less than $100{ }^{\circ} \mathrm{C}$ and maximum thermal fatigue stresses are low at $3.5 \times 10^{7} \mathrm{~Pa}(5 \mathrm{ksi})$. Rotation of the dump results in relatively low radiation damage levels with an operating lifetime of years for most beams.
\end{abstract}

\section{Introduction}

The Rare Isotope Accelerator (RIA) has an ISOL beam line with proton and helium beams and a Fragmentation beam line with heavy ion beams of $\mathrm{U}, \mathrm{Sn}, \mathrm{Kr}$, and $\mathrm{Ca}$. For the fragmentation line, the heavy ion beam first impinges on a target where a fraction $(20 \%)$ of the beam is absorbed and the rest of the beam passes through the first dipole magnet and is absorbed in a beam dump just downstream of the dipole magnet. The desired ions generated in the target are sent down the centerline of the accelerator and the beam, other ions and other fragments are absorbed in the beam dumps. The beam dump design consists of a rotating barrel shape with the beam partially absorbed in $2 \mathrm{~mm}$ of aluminum material and the rest of the beam absorbed in several $\mathrm{cm}$ of depth of flowing water behind the aluminum.

Analyses of the energy deposition of the beam in the dump material were made. The thermal and structural response of the dump due to the energy deposition was also analyzed. Rotation of the dump is necessary to reduce the volumetric energy deposition in the Al dump material and in the water coolant/absorber and to result in lower acceptable temperatures, thermal stresses and radiation damage.

\section{Mechanical Design}

The beam dumps for the fragmentation line are located downstream of the first dipole magnet and in front of the multipole magnet. The dump consists of two rotating barrel shapes that are placed to each side of the beam centerline. The dumps rotate about a 
horizontal axis. Figure 1 shows the two barrel dumps and related hardware. The dumps are located in a vacuum space surrounding the dipole magnet.

The dumps consist of two assemblies with each assembly consisting of a barrel shape with a shaft that penetrates a vacuum wall structure, a rotating vacuum pass-through at the vacuum wall, a water union coupling, an electric motor and drive belt, and an expansion joint with a motor to allow horizontal motion of each dump.

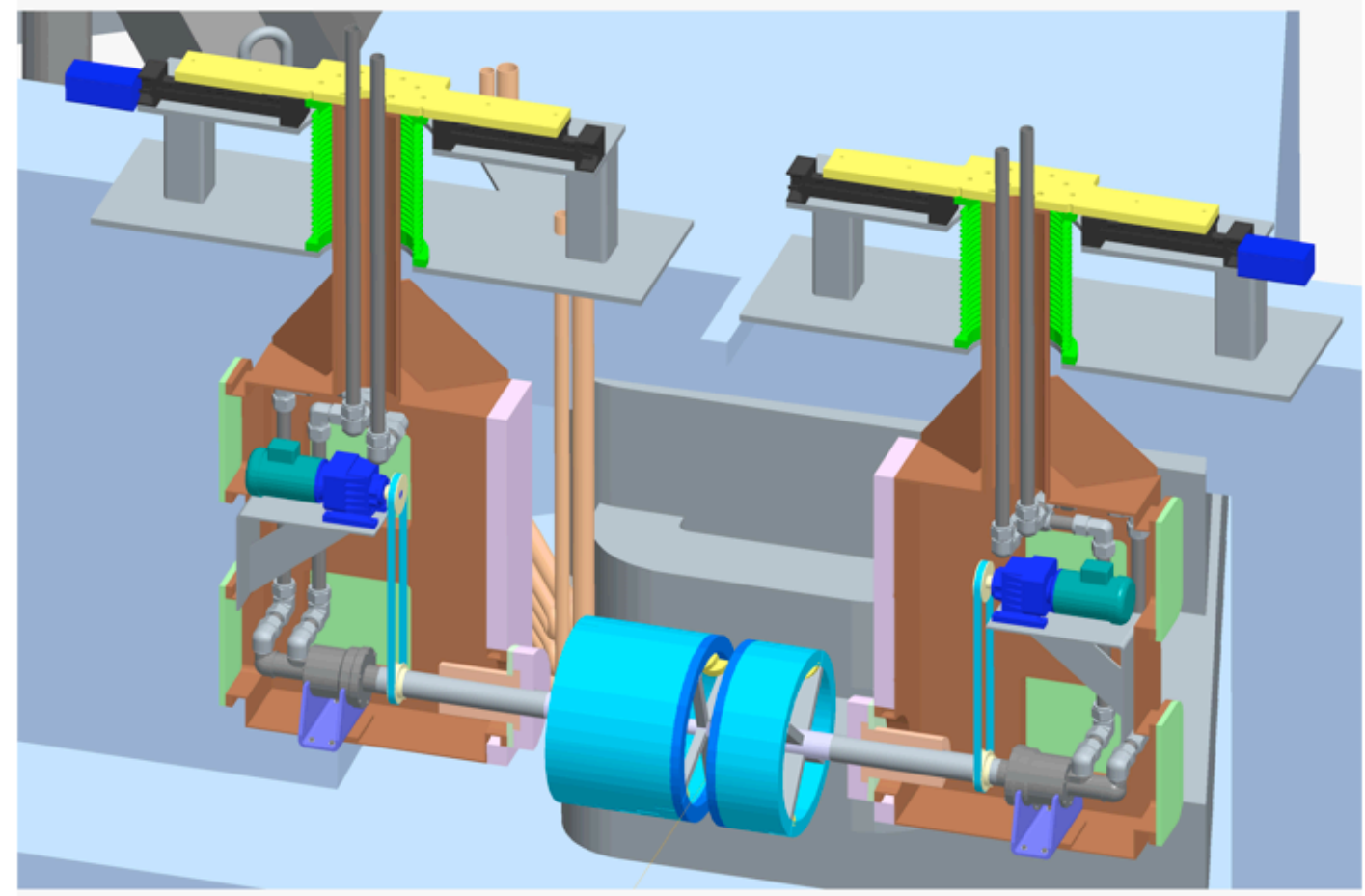

Figure 1. Barrel shaped beam dumps located downstream of the first dipole magnet.

Operation of the dumps involves rotating the barrels in order to spread out the beam power over the perimeter of the barrel. Water is used to cool the metal of the dumps and absorb the beam power that penetrates the barrel wall. The water cooling enters and exits the barrels along the rotating hollow shafts that are connected to the building water pipes with the water union. An electric motor is used to drive the rotation of the shaft and barrel.

The dump assembly support structure is part of the vacuum enclosure of the dipole magnet. The barrel shaft penetrates this support structure and a rotating vacuum pass- 
through is used seal the shaft penetration from the vacuum side to the air side containing the union and motor. The beam dump support structure is supported by an expansion joint assembly at the top of the dipole magnet vacuum enclosure for the purpose of allowing $10 \mathrm{~cm}$ of horizontal motion of the barrels. This motion is necessary for beam operating conditions where the main beam is only a few centimeters from the accelerator centerline. A support table and track is connected to the expansion joint to allow lateral motion by use of an electric motor.

\section{Detail of dump barrels}

Figure 2 shows the barrel geometry. The barrels have an outside diameter of $70 \mathrm{~cm}$ and are $50 \mathrm{~cm}$ or $28 \mathrm{~cm}$ long. The barrel material is an aluminum alloy and the outer wall thickness is $2 \mathrm{~mm}$. Water flows in the $6 \mathrm{~cm}$ deep channels to convectively cool the barrel wall and to act as an absorber of the fraction of the beam that is not absorbed by the

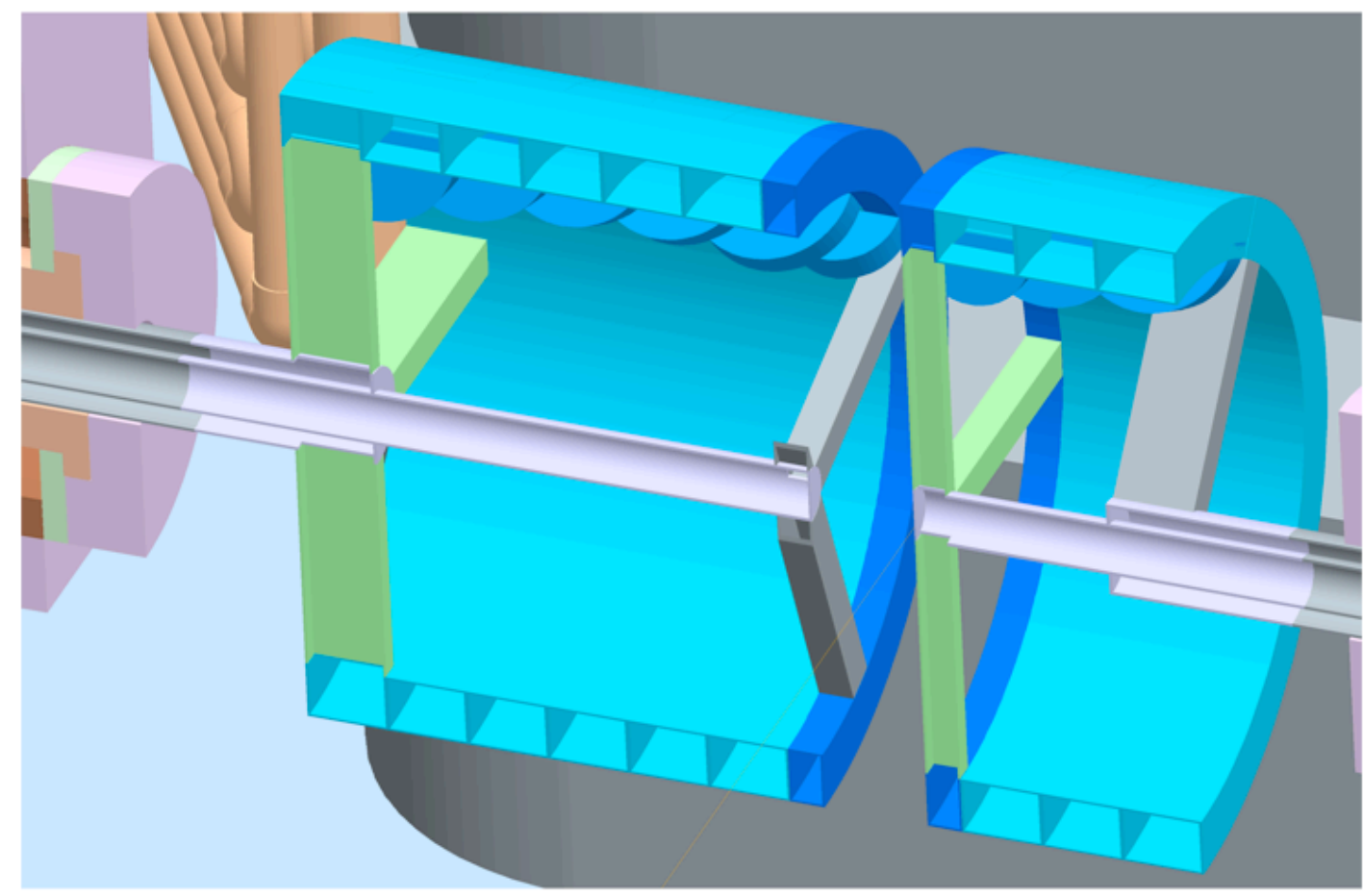

Figure 2. Barrel and shaft cross section

aluminum wall. The shaft consists of a 3 inch diameter inner pipe and a 4 inch diameter outer pipe. The water flow path is from the building supplied water pipe, through the 
rotating water union, to the inner pipe of the shaft, to a set of hollow spokes, to the water channels around the perimeter of the barrel, to a set of hollow spokes connecting to the outer return flow pipe of the shaft. Water flow velocities in the barrel channels are expected to vary between $9 \mathrm{~m} / \mathrm{s}$ to $3 \mathrm{~m} / \mathrm{s}$. The water volume flow rate is 4 gps. Water pressure drop in the barrels is 8 psi.

The barrels are rotated at a nominal 400 RPM, in the same direction as the water flow direction in the channels along the barrel perimeter. For dump operation with the small spot size $(1 \mathrm{~cm})$ Uranium beam at full power, it is necessary to rotate the right barrel at 600 RPM in order to keep temperatures and stresses at acceptable levels.

Figure 3 shows a schematic of the beam dump assembly.

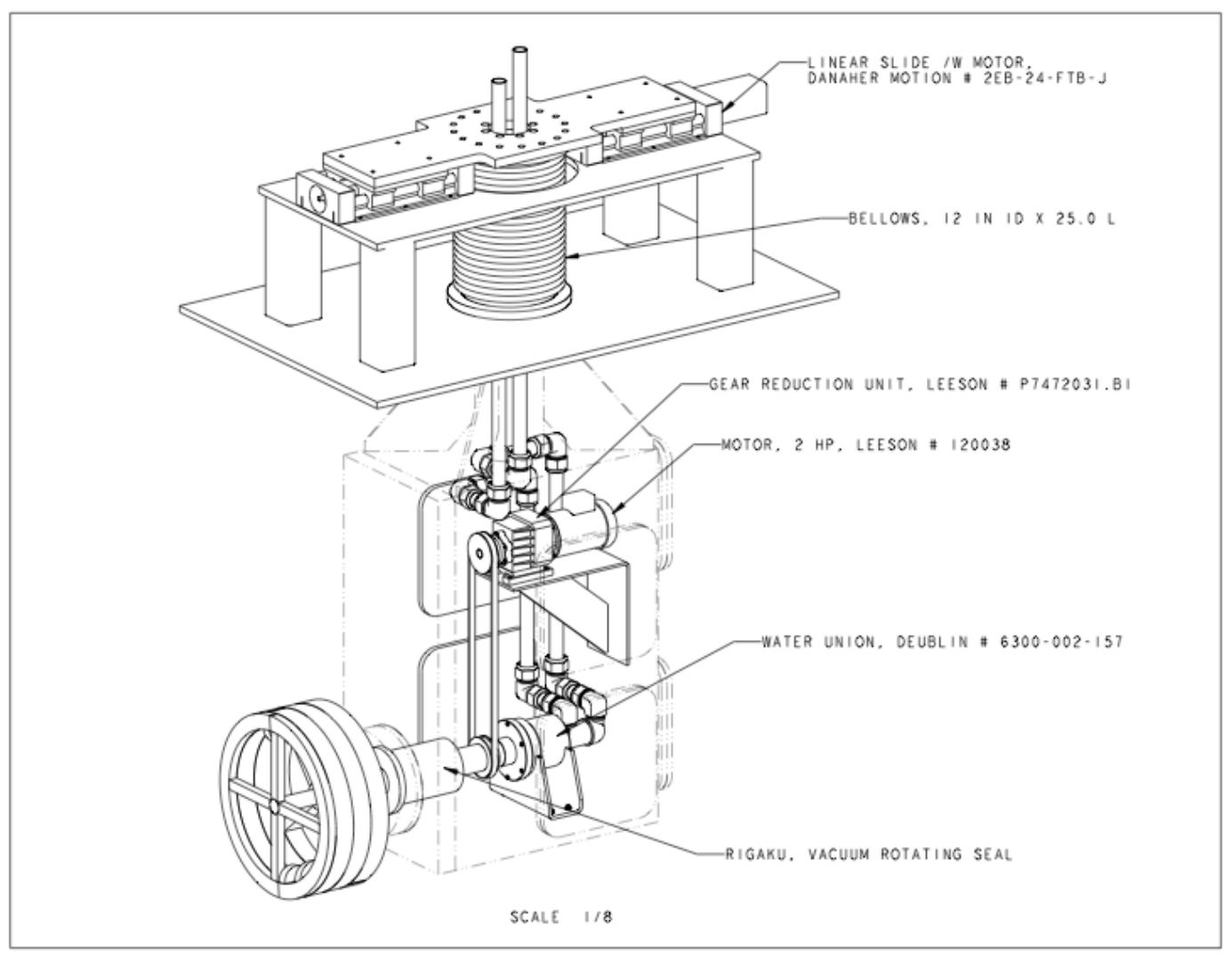

Figure 3. Schematic of a barrel shaped beam dump.

\section{Rotating vacuum pass-through}

The mechanical operation of the vacuum pass-through from the point of sealing capability and operational lifetime in the radiation and magnetic field environment 


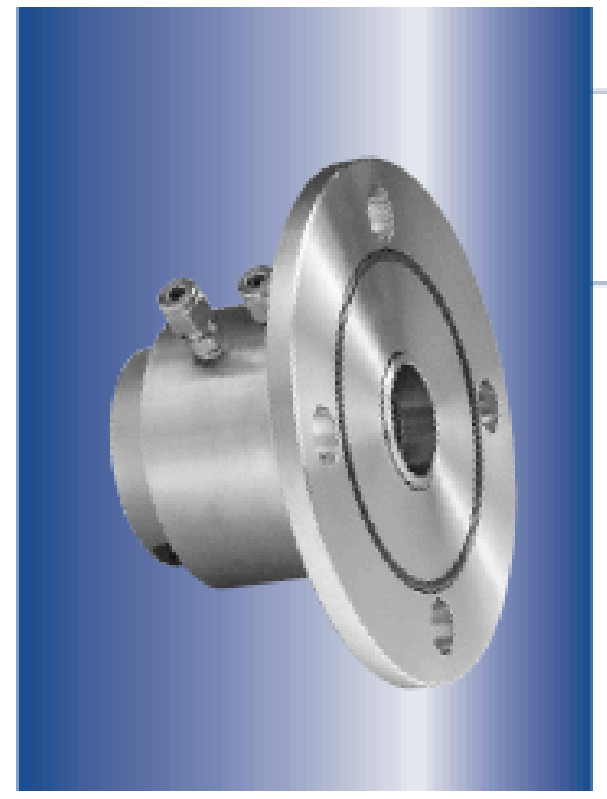

\section{Hollow Shaft Flange Mount Feedthroughs}

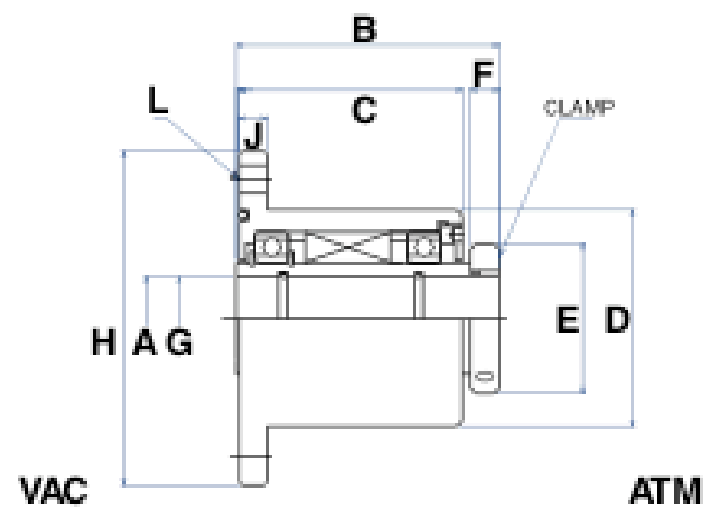

4Sass

Figure 4. Rotating vacuum pass-through for barrel shaft vacuum wall penetration.

is of considerable concern. Commercial products by Ferrotec and Rigaku, figure 4, appear to meet our requirements. For anticipated shaft loads and 400 RPM, the manufacturers anticipate operating lifetimes of years. The pass-throughs can operate in magnetic fields up to one Tesla. Operation in the RIA anticipated radiation environment will have an affect on the ferro-fluids and permanent magnets in the pass-throughs. Based on radiation field calculations presented in section 5 of this report, acceptable lifetimes can be had for the ferro-fluid and the magnet. Further study of radiation damage effects on magnets is necessary, however, the problem may be engineered away by placing additional shielding around the pass-through.

\section{Beam dump heavy Ion beam parameters}

Anticipated operation of the RIA fragmentation line includes the beams listed in table 1 (1). The beam of major concern is the Uranium beam with almost $300 \mathrm{~kW}$ of power and a $5 \mathrm{~cm}$ spot size. Other beams include a $\mathrm{Xe}, \mathrm{Kr}, \mathrm{Sn}$, and $\mathrm{Ca}$ beam. 


\begin{tabular}{|c|c|c|c|c|c|c|c|}
\hline Fragment & Beam & $\begin{array}{l}\text { Charge } \\
\text { State }\end{array}$ & $\begin{array}{l}\text { Beam } \\
\text { Power in } \\
\text { Target (kW) }\end{array}$ & $\begin{array}{l}\text { Dump } \\
\text { Power } \\
(\mathrm{kW})\end{array}$ & $\begin{array}{l}\text { Beam } \\
\text { Range in } \\
\text { Cu (cm) }\end{array}$ & $\begin{array}{l}\text { Beam } \\
\text { Range } \\
\text { in } \mathrm{Al} \\
(\mathrm{cm})\end{array}$ & $\begin{array}{l}\text { Beam } \\
\text { Range in } \\
\text { Graphite } \\
\text { (cm) }\end{array}$ \\
\hline $122 \mathrm{Zr}$ & $136 \mathrm{Xe}$ & 54 & 153 & 247 & 0.36 & 1 & 1.1 \\
\hline $130 \mathrm{Cd}$ & $136 \mathrm{Xe}$ & 54 & 139 & 261 & 0.45 & 1.3 & 1.36 \\
\hline $78 \mathrm{Ni}$ & $86 \mathrm{Kr}$ & 36 & 150 & 250 & & & \\
\hline $22 \mathrm{C}$ & $48 \mathrm{Ca}$ & 20 & 166 & 234 & 0.57 & 1.62 & 1.7 \\
\hline \multirow[t]{6}{*}{$200 \mathrm{~W}$} & $238 U$ & & 102 & & & & \\
\hline & & 92 & & 11.92 & & & \\
\hline & & 91 & & 86.42 & & & \\
\hline & & 90 & & 178.8 & & & \\
\hline & & 89 & & 17.88 & & & \\
\hline & & 88 & & 0.894 & & & \\
\hline $100 \mathrm{Sn}$ & $112 \mathrm{Sn}$ & 50 & 186 & & & & \\
\hline
\end{tabular}

Table 1. RIA beams and fragments

The beam dumps physical axial dimensions are designed to intercept the above beams, with some of the beams hitting the left beam dump and some the right beam dump of figure 2. The relative location of the beams of Table 1 are shown in figure 5. The barrel dumps are designed to intercept all the beams of figure 5 except the Ca beam. For this beam, a separate stationary dump has been designed and is described in section 15 of this report. 


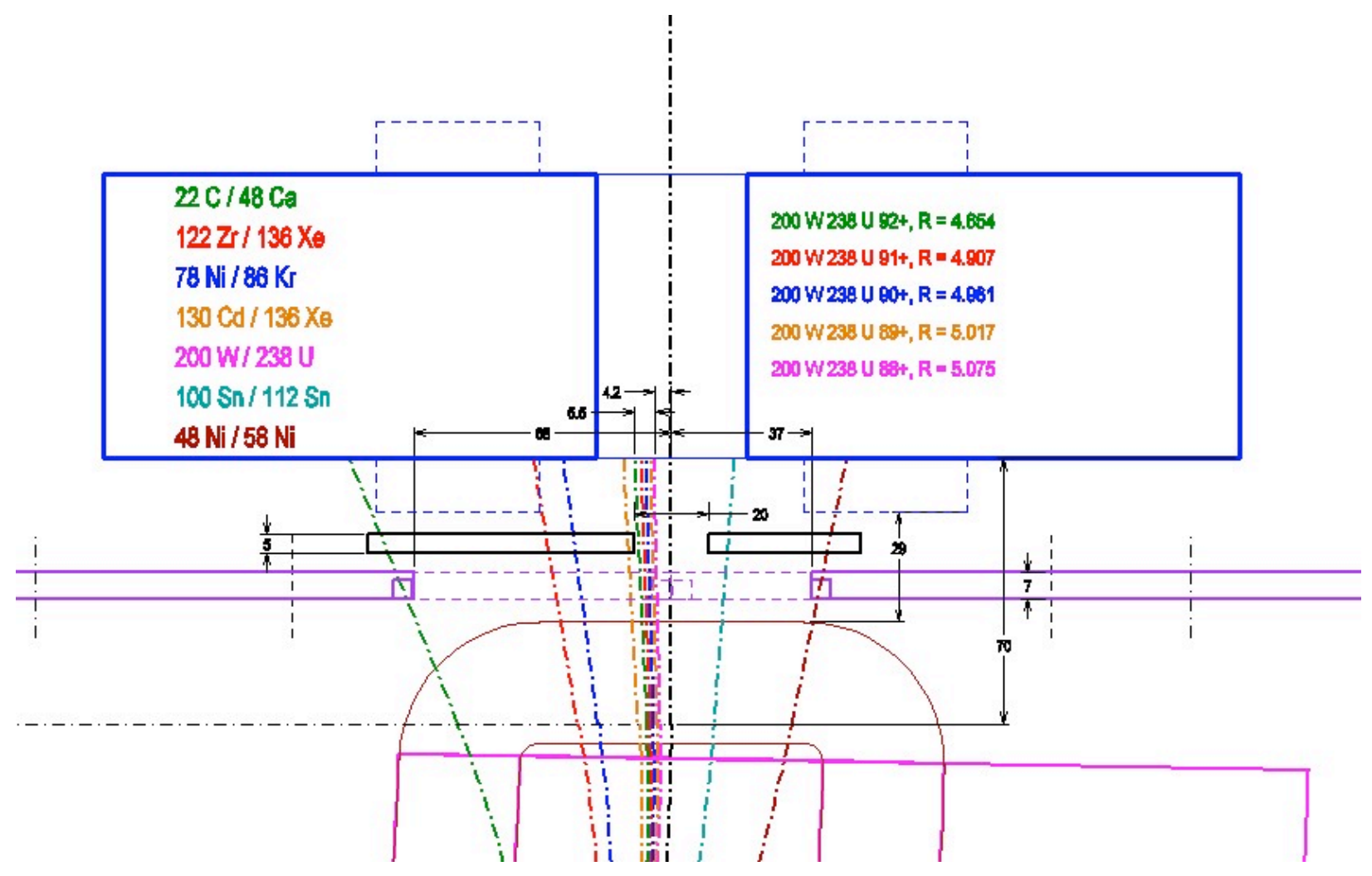

Figure 5. Beam location relative to the accelerator centerline.

\section{Beam energy absorption in $\mathrm{Al}$ and water}

The operation of the beam dumps involves the use of $\mathrm{Al}$ and water to absorb the beams. The Al outer wall of the barrel essentially acts as a window for the beam and the water behind the $\mathrm{Al}$ acts to absorb the remainder of the beam. In the calculations for temperatures and thermal stress in the barrel for the various beams, the data in table 2 applies. The table shows the fraction of each beam's energy absorbed in $2 \mathrm{~mm}$ of $\mathrm{Al}$ and the water depth required to absorb all of a beam's power.

\begin{tabular}{|c|c|c|}
\hline Beam & $\begin{array}{l}\text { Fraction absorbed in } \\
2 \mathrm{~mm} \text { of } \mathrm{Al} \quad(\%)\end{array}$ & $\begin{array}{l}\text { Water depth required to } \\
\text { absorb the beam }\end{array}$ \\
\hline U $320 \mathrm{Mev} / \mathrm{u}$ & 15 & $2 \mathrm{~cm}$ \\
\hline $\mathrm{Ca} 272 \mathrm{Mev} / \mathrm{u}$ & 5 & 5.2 \\
\hline $\mathrm{Xe} 326 \mathrm{Mev} / \mathrm{u}$ & 10 & $2.8 \mathrm{~cm}$ \\
\hline $\mathrm{Kr} 325 \mathrm{Mev} / \mathrm{u}$ & 7 & $3.9 \mathrm{~cm}$ \\
\hline Sn $267 \mathrm{Mev} / \mathrm{u}$ & 14 & $2 \mathrm{~cm}$ \\
\hline
\end{tabular}

Table 2. RIA heavy ion beam absorption in Al and water. 


\section{7. $U$ and Ca beam spot sizes}

A typical $\mathrm{U}$ beam impacting the beam dump has a power of $295 \mathrm{~kW}$ and has a profile in the horizontal direction as shown in figure 6. The beam ions have an energy of $320 \mathrm{Mev}$ per nucleon.

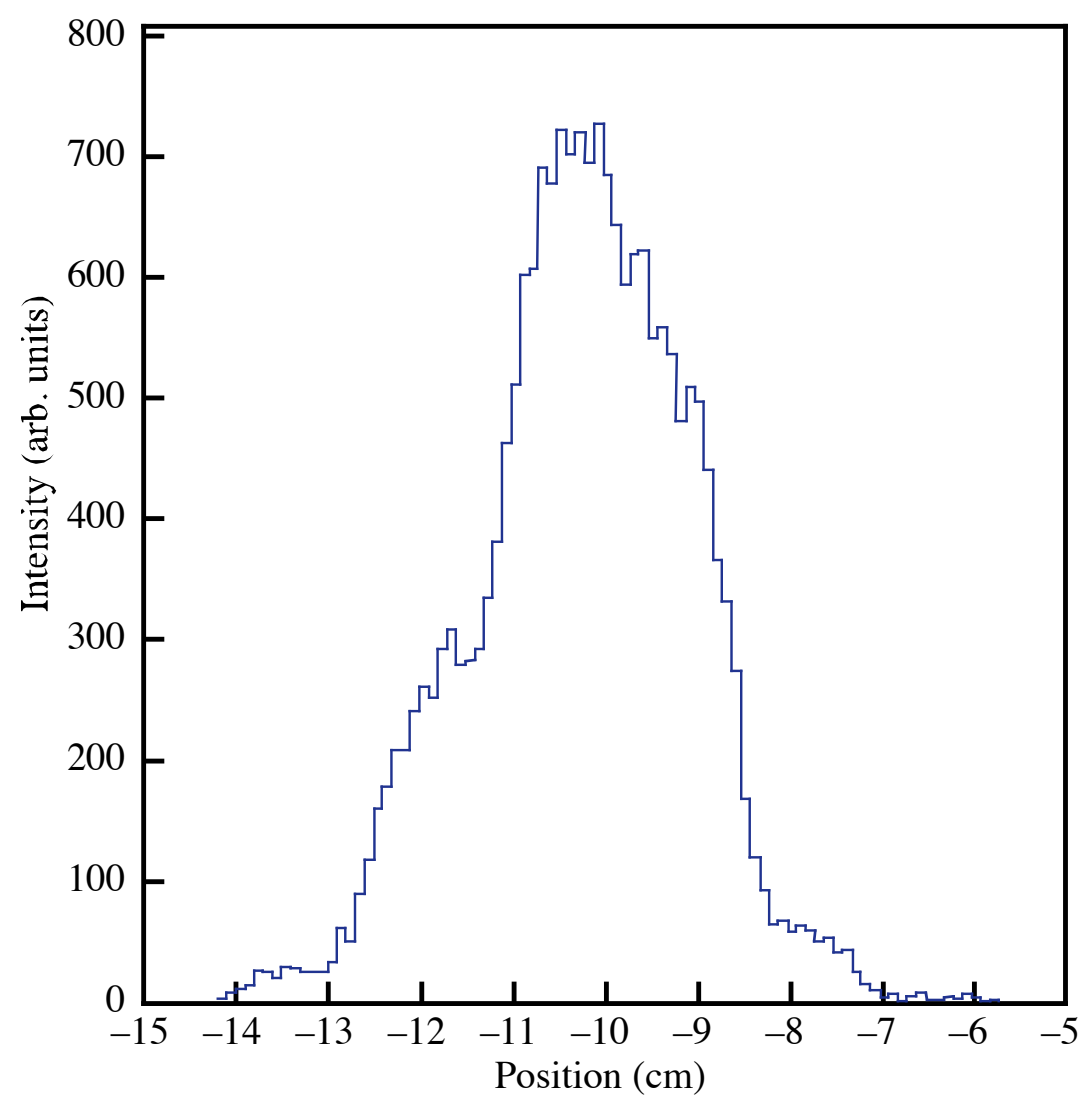

Figure 6: U beam horizontal profile [1].

The Ca beam of Table 1 has a spot size discernable from figure 7 below (2). The spot size is approximately $5 \mathrm{~cm}$ horizontal by $40 \mathrm{~cm}$ vertical with a power of $234 \mathrm{~kW}$ spread over the beam size shown in the figure. Absorbing this beam can be accomplished by a stationary water cooled beam dump described in section 15 . 


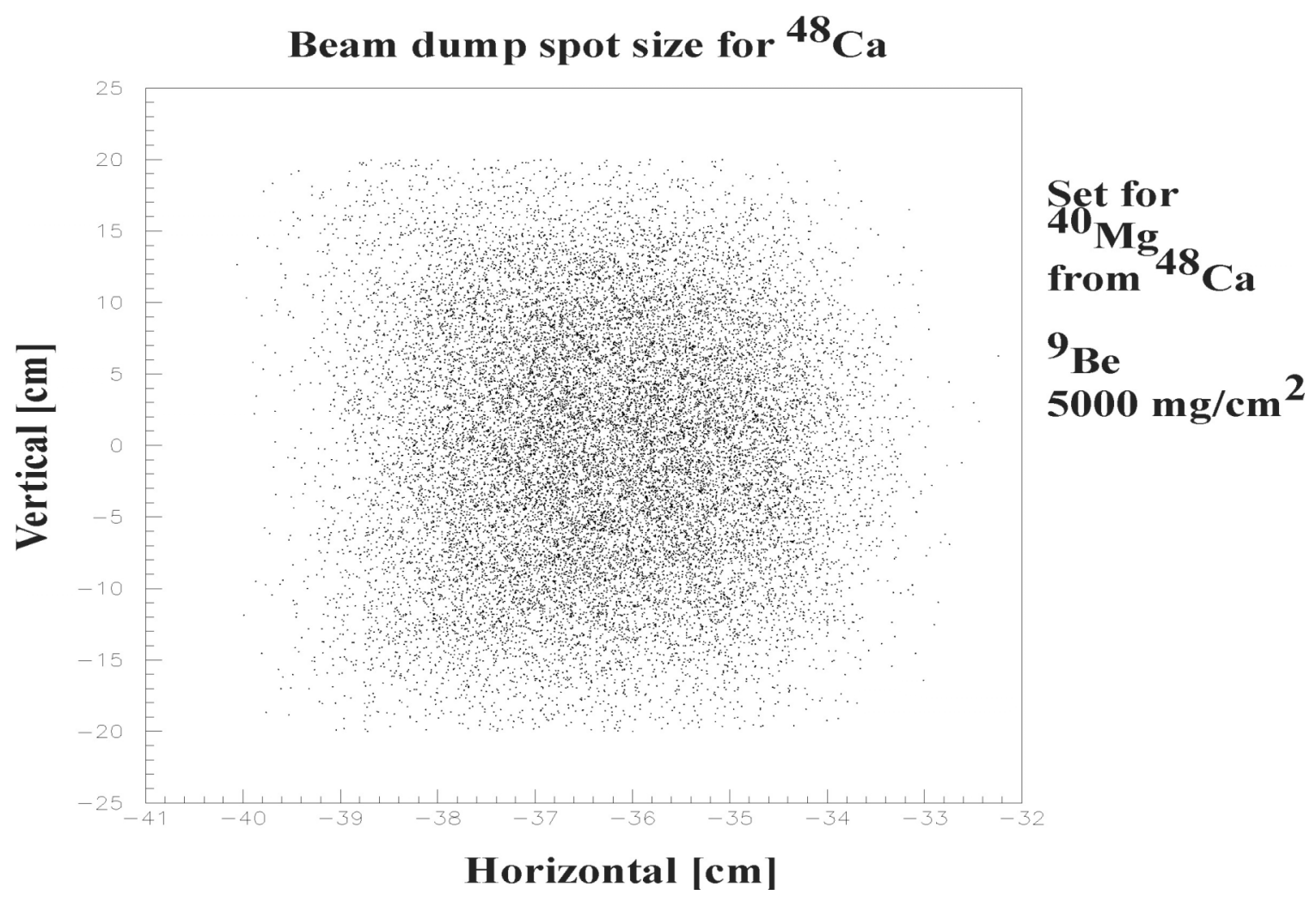

Figure 7. Ca beam spot size is $5 \mathrm{~cm} \mathrm{x} 40 \mathrm{~cm}$.

\section{Radiation damage from $U$ beams}

The impact of the $\mathrm{U}$ beam on the Al wall of the barrel results in radiation damage in the material. This damage results in a degradation of the structural properties of the material including loss of ductility and brittleness. To estimate the damage in the Al material, a simulation of damage quantified by displacements of atoms per atom , DPA, was made (3) and the results shown in figure 8. The PHITS code was used to simulate a $\mathrm{U}$ beam passing through a window of $\mathrm{Al}$ or Be with a thickness of 1 or $2 \mathrm{~mm}$. The beam is assumed uniformly spread out over a $3 \mathrm{~cm} \times 3 \mathrm{~cm}$ area. The results show that for a 2 $\mathrm{mm} \mathrm{Al}$ window that $9.9 \times 10^{-3} \mathrm{DPA} /$ day are generated by the $\mathrm{U}$ beam over a $3 \mathrm{~cm} \times 3 \mathrm{~cm}$ area. For the case of a rotating barrel surface, this damage is spread out over a surface area of nominally $5 \mathrm{~cm} \mathrm{x} 220 \mathrm{~cm}$ (perimeter of barrel) and results in a value of $2.3 \times 10^{-4}$ DPA/day. For an estimated allowable value of 5 DPA, this results in a lifetime of years. 
If the $\mathrm{U}$ beam were completely stopped by $\mathrm{Al}$ material, the peak value of damage at a depth of $7 \mathrm{~mm}$ would be $3 \mathrm{DPA} /$ day if the beam was deposited over a $3 \mathrm{~cm} \times 3 \mathrm{~cm}$ area. For our case the surface area is $5 \mathrm{~cm} \times 220 \mathrm{~cm}$ and the damage is $7 \times 10^{-2} \mathrm{DPA} /$ day which gives a lifetime of 8 weeks for an allowable dose of 5 DPAs. For the barrel designs, there are spacer ribs separating the water channels that may see higher DPA values but the beams are expected to primarily impact only in regions of the $2 \mathrm{~mm}$ thick $\mathrm{Al}$ wall.

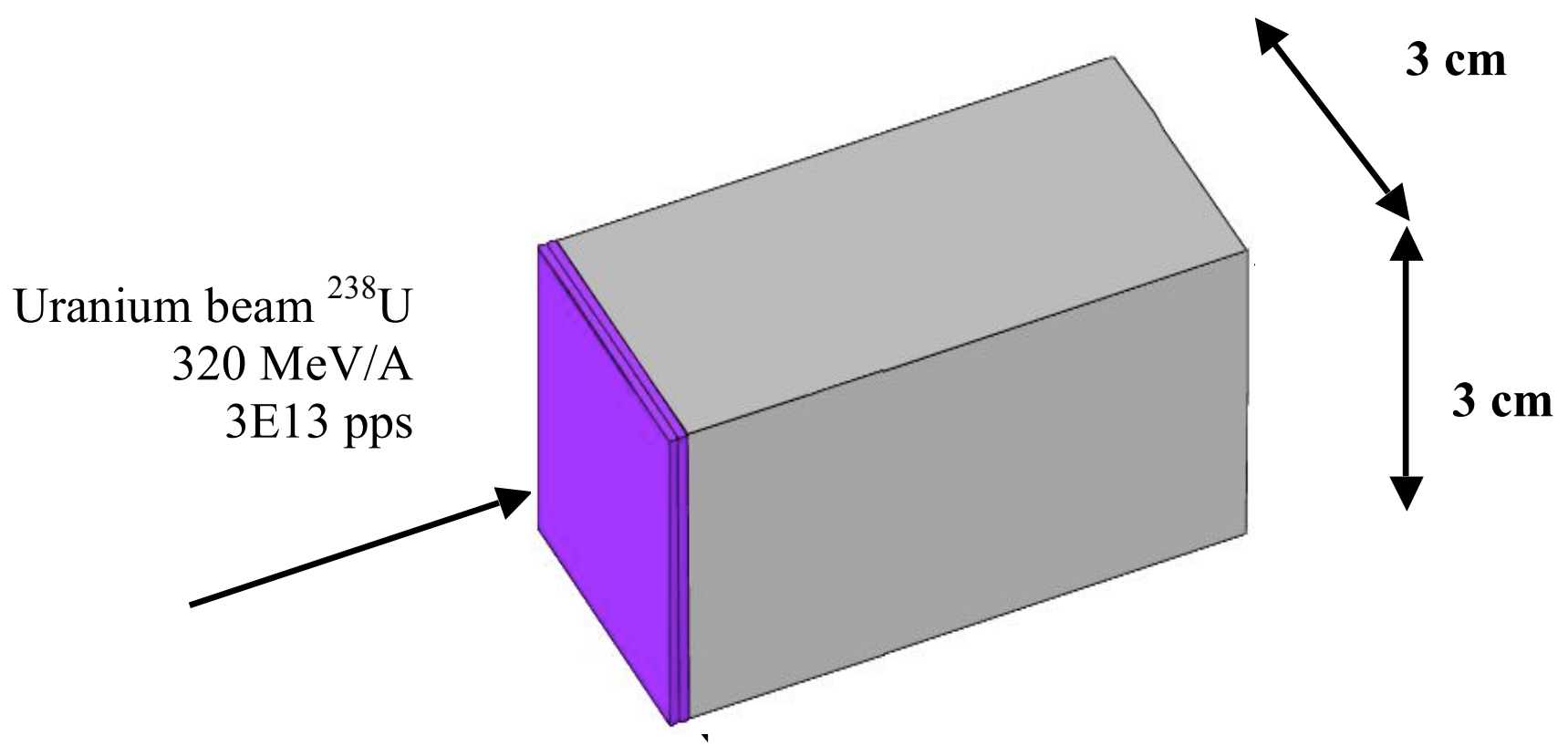

\begin{tabular}{|c|c|}
\hline Be window & DPA / day \\
\hline $0-1 \mathrm{~mm}$ & $1.3 \mathrm{E}-03$ \\
\hline $1-2 \mathrm{~mm}$ & $1.4 \mathrm{E}-03$ \\
\hline
\end{tabular}

\begin{tabular}{|c|c|}
\hline Al window & DPA / day \\
\hline $0-1 \mathrm{~mm}$ & $8.2 \mathrm{E}-03$ \\
\hline $1-2 \mathrm{~mm}$ & $9.9 \mathrm{E}-03$ \\
\hline
\end{tabular}

Figure 8. PHITS DPA calculations for Be and Al windows

The $\mathrm{U}$ beam impacting the barrel $\mathrm{Al}$ surface and water coolant results in a prompt dose of radiation on the materials of the vacuum pass-through. For this equipment the $\mathrm{NdFeB}$ magnet material and FerroFluid liquid material may be susceptible to radiation damage and Table 3 gives an estimate that allowable limits are not exceeded after 4 
months of operation (4). Some additional shielding was placed around the pass-through to result in acceptable lifetimes.

\begin{tabular}{|l|c|c|c|}
\hline Material & Density (g/cc) & Effective dose (MGy/yr) & Limit (MGy) \\
\hline NdFeB & 6 & 0.05 & 0.1 \\
\hline SmCo & 8.82 & 0.30 & 100 \\
\hline Kapton & 1.42 & 0.19 & 10 \\
\hline FerroFluid & 1.42 & 0.69 & $>1 ?$ \\
\hline
\end{tabular}

Table 3. Radiation transport results, prompt dose and DPA values.

\section{Barrel temperature response due to a $\mathbf{U}$ beam}

A U beam with a $5 \mathrm{~cm}$ wide spot size deposits energy into the $2 \mathrm{~mm}$ thick Al wall of the barrel as it rotates past the beam impact point. Approximately $15 \%$ of the $295 \mathrm{~kW}$ power of the beam is deposited in the $2 \mathrm{~mm}$ of the Al wall and $85 \%$ is deposited in the water cooling this surface. The thermal response of the wall is that of a temperature jump as $\mathrm{Al}$ material rotates past the beam. The temperature jump is then relaxed by conduction in the $\mathrm{Al}$ and by convective heat transfer to the adjacent cooling water. The temperature jump is dependent on the velocity of the perimeter of the barrel. For a perimeter velocity of $14.7 \mathrm{~m} / \mathrm{s}$ (400 RPM) the temperature jump is as shown in figure 9 . This figure shows the results of a thermal calculation (using Topaz-3d [5]) and shows a temperature jump of $19{ }^{\circ} \mathrm{C}$ as the beam of figure 5 impacts the dump material. Every time the Al material rotates past the beam a similar $19{ }^{\circ} \mathrm{C}$ jump occurs and then this temperature relaxes back down to a steady state condition due to the convective heat transfer to the water coolant. 


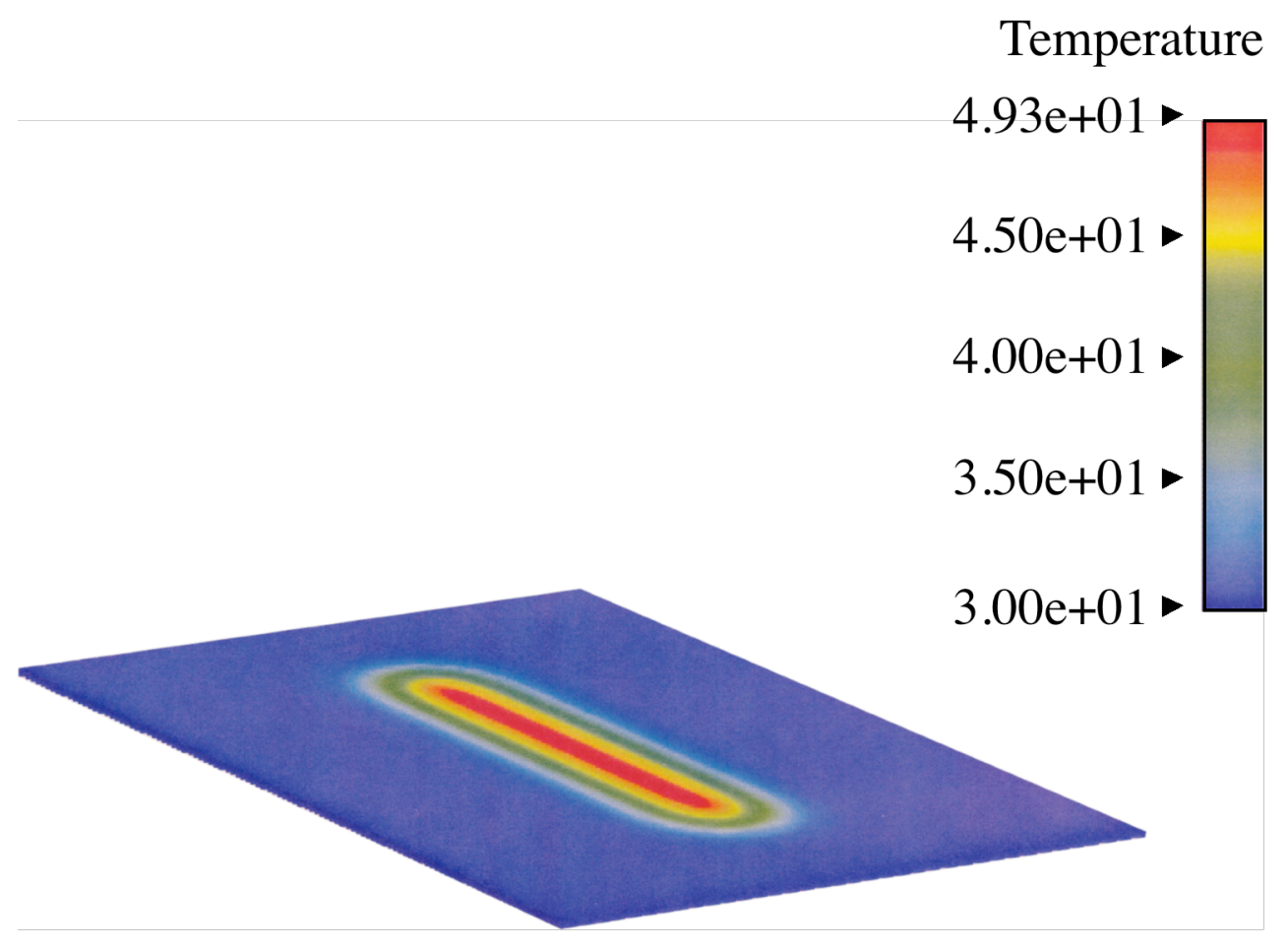

Figure 9. Temperature, ${ }^{\circ} \mathrm{C}$, jump as the $\mathrm{U}$ beam penetrates and moves along the aluminum material of the dump barrel.

\section{Cooling water heat transfer response - U beam}

Water is used to cool the beam dump aluminum material and is used to absorb the portion of the beam that passes through the aluminum outer surface of the barrel. The water velocity along the barrel surface is 9 to $3 \mathrm{~m} / \mathrm{s}$ and results in a convective heat transfer coefficient of $9 \mathrm{~kW} / \mathrm{m}^{2}-{ }^{\circ} \mathrm{C}$ (for $3 \mathrm{~m} / \mathrm{s}$ ) based on Nusselt correlations. With this heat transfer coefficient, the aluminum metal temperature in the heated ring region around the barrel will be an average of $45^{\circ} \mathrm{C}$ above the channel water temperature. This temperature rise is calculated from a convection cooling heat balance calculation:

$$
\begin{aligned}
\mathrm{Q} \times \mathrm{f} & =\mathrm{h} \times \mathrm{A} \times \mathrm{dT} \\
\mathrm{dT} & =45^{\circ} \mathrm{C}
\end{aligned}
$$

$\mathrm{Q}=$ beam power of $295 \mathrm{~kW}$

$\mathrm{f}=$ fraction of beam power absorbed in the $2 \mathrm{~mm} \mathrm{Al}$ wall, $15 \%$

$\mathrm{h}=$ convective heat transfer coefficient for $3 \mathrm{~m} / \mathrm{s}$ water velocity, $9 \mathrm{~kW} / \mathrm{m}^{2}-{ }^{\circ} \mathrm{C}$

$\mathrm{A}=$ barrel surface area impacted by the $\mathrm{U}$ beam, $220 \mathrm{~cm} \times 5 \mathrm{~cm}$

$\mathrm{dT}=$ barrel average surface temperature above coolant temperature

As the water flows by the beam penetration region on the barrel surface, approximately $85 \%$ of remaining beam power is absorbed in the $2 \mathrm{~cm}$ depth of the water. A heat 
balance calculation for the volume flow rate of water and the energy deposition rate of the beam results in an estimate of the water temperature jump:

$$
\begin{aligned}
\mathrm{Q} \times \mathrm{f} & =\text { Vel } \times \text { A x Rho } \times \mathrm{Cp} \times \mathrm{dT} \\
\mathrm{dT} & =4{ }^{\circ} \mathrm{C}
\end{aligned}
$$

$\mathrm{Q}=$ beam power of $295 \mathrm{~kW}$

$\mathrm{f}=$ fraction of beam power absorbed in the $2 \mathrm{~cm}$ depth of water, $85 \%$

$\mathrm{Vel}=$ water velocity past the beam, $10 \mathrm{~m} / \mathrm{s}$ surface velocity $+3 \mathrm{~m} / \mathrm{s}$ water velocity

$\mathrm{A}=$ cross sectional area of water flow absorbing the $\mathrm{U}$ beam, $5 \mathrm{~cm} \times 2 \mathrm{~cm}$

$\mathrm{dT}=$ water temperature jump

Rho = water density, $1000 \mathrm{~kg} / \mathrm{m}^{3}$

$\mathrm{Cp}=$ heat capacity of water, $4200 \mathrm{~J} / \mathrm{kg}-{ }^{\circ} \mathrm{C}$

This $\mathrm{dT}=4{ }^{\circ} \mathrm{C}$ represents the water temperature jump if the beam deposited its energy uniformly in the water but there is a peak value that is approximately 5 times greater near the end of the deposition range and thus the localized peak temperature jump may be as high as $20 \mathrm{C}$. This peak temperature may be, however, mitigated somewhat by the turbulence of the water.

Thus if $15{ }^{\circ} \mathrm{C}$ water is used as a coolant, then the maximum temperature that the $\mathrm{Al}$ reaches is approximately $70^{\circ} \mathrm{C}$.

\section{Thermal stress structural response of aluminum surface $-U$ beam}

The beam impacts the rotating aluminum material of the dump and causes a rapid temperature jump or rise over the spot dimension of the beam along the direction of rotation of the dump. This increase in the aluminum temperature results in thermal stresses in the Al due to the material trying to expand. The resultant stress from this energy deposition was modeled using a structural analysis code (Dyna3d [6]). Figure 10 shows the results of the calculations with a peak stress of $3 \mathrm{ksi}\left(2.14 \times 10^{7} \mathrm{~Pa}\right)$. The allowable fatigue stress for aluminum alloys may be as high as $20 \mathrm{ksi}\left(1.4 \times 10^{8} \mathrm{~Pa}\right)$ and thus the calculated stress is well below allowable limits. The relatively low stresses therefore suggest that the barrel RPM could be lowered to values closer to 200 RPM. 


\section{Effective Stress}

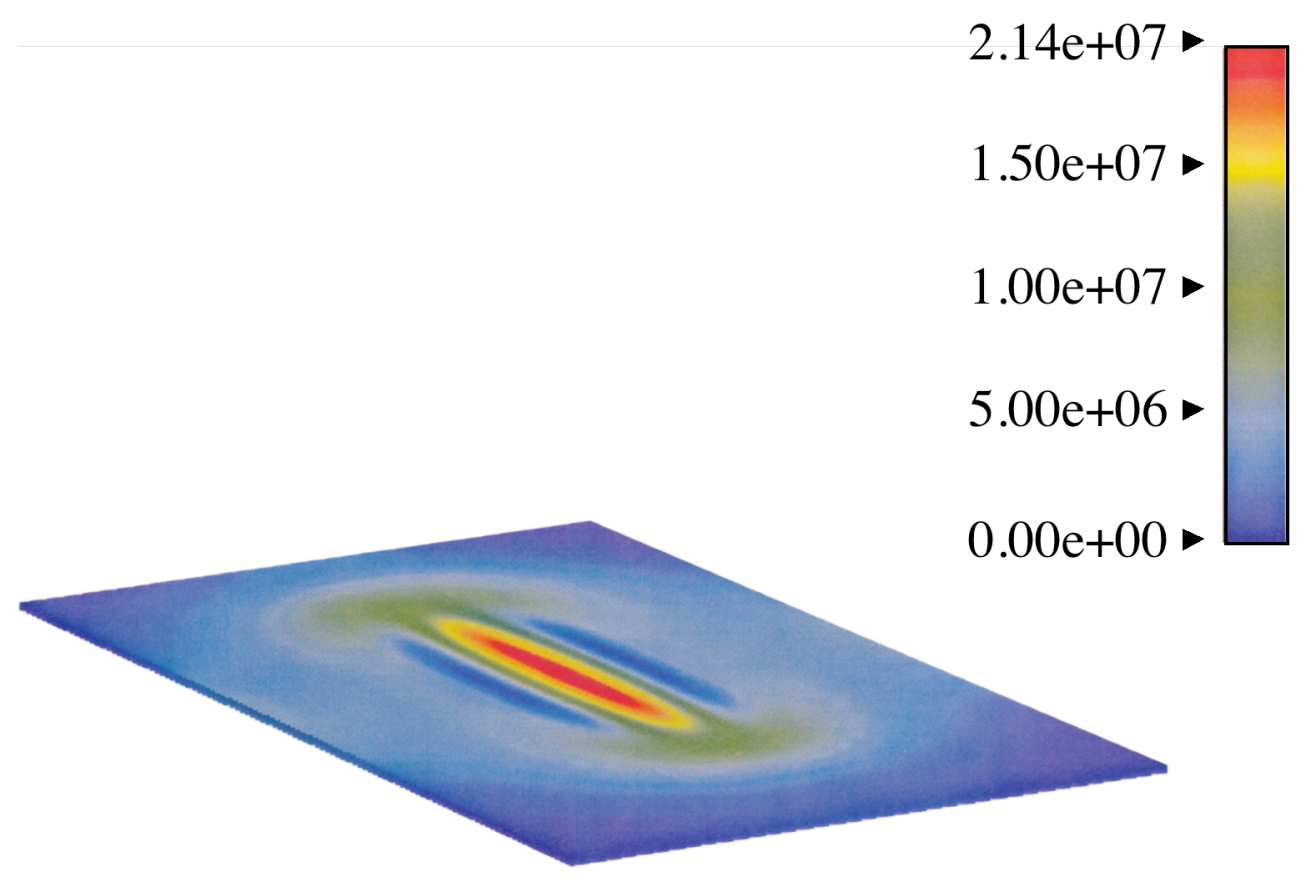

Figure 10.Thermal stress, $\mathrm{Pa}$, in the aluminum window of the barrel dump due to a $U$ beam $(5 \mathrm{~cm}$ spot size) penetration.

\section{Dump performance for $1 \mathrm{~cm}$ spot size $U^{+92}$ beam}

The most severe beam profile is for an essentially fully ionized $U$ beam with a narrow spot size as shown in figure 11. The $\mathrm{U}^{+90}$ charge state here is the part of the beam of most concern because its width is less than $1 \mathrm{~cm}$ and its power is high at $184 \mathrm{~kW}$. This beam impacts the dumps very near the accelerator ion/particle centerline and very near the edge of the dump.

To accommodate this $\mathrm{U}^{+90}$ beam, the barrel is rotated at a more rapid rate, $600 \mathrm{RPM}$, and this results in a maximum expected $\mathrm{Al}$ wall temperature jump of $40{ }^{\circ} \mathrm{C}$ and a thermal stress of $6 \mathrm{ksi}$. For this beam the water channel velocity is $9 \mathrm{~m} / \mathrm{s}$, and the peak water temperature jump is $30^{\circ} \mathrm{C}$. Radiation damage in the $2 \mathrm{~mm}$ Al barrel wall is still expected to be low and result in Al wall lifetimes of years for an allowable 5 DPA level.

\section{Dump performance for other heavy ion beams, $\mathrm{Ca}, \mathrm{Sn}, \mathrm{Kr}, \mathrm{Xn}$, and $\mathrm{Ni}$.}

Other driver beams besides the $\mathrm{U}$ beam, such as $\mathrm{Ca}, \mathrm{Sn}, \mathrm{Kr}, \mathrm{Xn}$, and $\mathrm{Ni}$ beams, are expected to have ranges of spot sizes and powers similar to the $U$ beams. For these beams, the barrel dump is expected to operate under less severe thermal, structural, and radiation damage conditions. 
The energy deposition range of these other beams in $\mathrm{Al}$ and water is greater than that of the $U$ beams and thus some beams may pass through one side of the beam dump and impact the far side of the beam dump. To avoid any beams impacting the centerline shaft, the shaft centerline is raised $10 \mathrm{~cm}$ above the accelerator beam line.

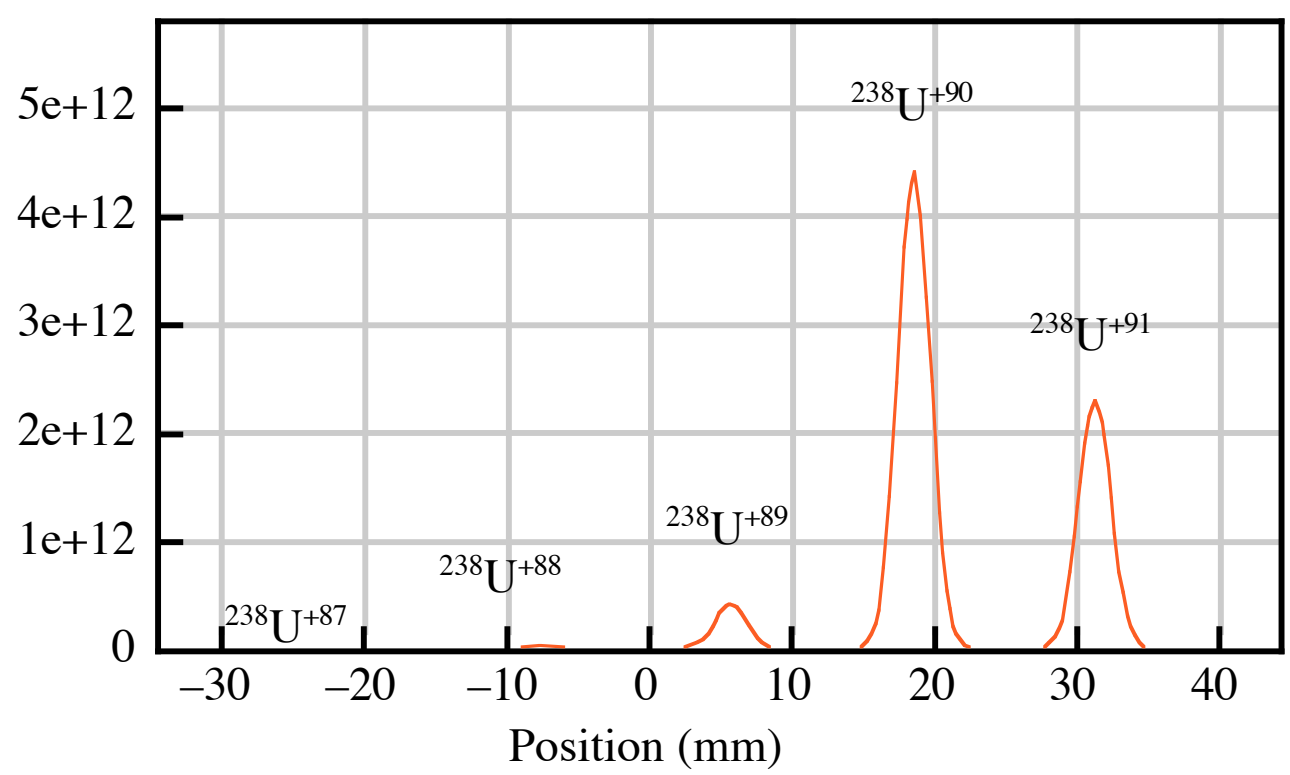

Figure 11. Narrow width $\mathrm{U}^{+90}$ charge state beam, $184 \mathrm{~kW}$ [2].

\section{Magnetic force field effects on dump rotation}

The rotation of the barrels in a strong magnetic field will result in forces retarding motion. A simplified estimate to quantify the horsepower (Watts) required to power the turning of the dumps was made.

For an estimated magnetic B field of 0.25 Tesla and perimeter velocity of the barrel of $10 \mathrm{~m} / \mathrm{s}$ and $\mathrm{Al}$ material, the power, $\mathrm{P}$, required is given by:

$$
\begin{aligned}
& \mathrm{P}=\mathrm{Vel}^{2} \times \mathrm{B}^{2} \times \mathrm{Vol} / \text { Res } \\
& \mathrm{P}=8 \mathrm{Hp}
\end{aligned}
$$

Where $\mathrm{P}=$ horsepower required to rotate the barrel

$\mathrm{Vel}=$ barrel surface rotational velocity, $10 \mathrm{~m} / \mathrm{s}$

$\mathrm{B}=$ magnetic field, 0.25 Tesla

$\mathrm{Vol}=$ volume of $\mathrm{Al}$ material rotating past the $\mathrm{B}$ field, $25 \mathrm{~cm} \times 2 \mathrm{~mm} \times 10 \mathrm{~cm}$ Res $=$ resistivity of $\mathrm{Al}$, estimate at $5 \times 10^{-8} \mathrm{Ohm}-\mathrm{m}$ 
Further refinements to the design to reduce magnetic fields, operating conditions and electric currents in the Al metal of the dump may result in considerably lower powers.

\section{Stationary beam dumps (Ca beams)}

For some cases of beam rigidity, the beams curve sufficiently that they exit the dipole magnet cavity toward one side and do not impact on the barrel beam dumps. For these beams, the spot sizes are large and thus they can be absorbed by a non rotating beam dump. A typical beam of this type is the Ca beam of Table 1, and figures 5 and 7 . For this Ca beam, a stationary beam dump can be used to absorb this beam.

Figure 12 shows one possible design that consists of an arrangement of two banks of tubes. The tubes are arranged so they intercept all beams exiting along one side of the dipole magnet. For some beams, the beam penetrates through one tube and is absorbed in the tube of the second banks of tubes. The beams are expected to impact the dump surface at angles of $30^{\circ}$ or less and also a significant fraction of the beam impacts inside the dipole magnet cavity. The dump physical design involves 5 to $8 \mathrm{~cm}$ diameter pipes with $1 / 2 \mathrm{~mm}$ thick Al walls with water flow to cool the wall and absorb the penetrating beam. Water velocities in the $5 \mathrm{~cm}$ diameter tubes is $5 \mathrm{~m} / \mathrm{s}$ with a volume flow rate of 5 gps.

The beam dump tube wall maximum temperatures are nominally $50{ }^{\circ} \mathrm{C}$ above the water bulk temperature and thermal stresses are less than $5 \mathrm{ksi}$ for any of the beams that may impact the stationary dump.

Radiation damage of the dump is expected to allow a minimum continuous operating time of 3 months but with expected RIA operating scenarios a lifetime of greater than a year is expected.

\section{Beam dump maintenance/repair}

Maintenance of the dumps is currently envisioned by removing a section of the floor above the dipole magnet vacuum cavity and using a crane to vertically lift the dumps up to the above crane access hall. From there the dumps will be moved to a remote repair room. Before lifting the dumps out, remote actuators will be required to disconnect water lines, electric lines, and break vacuum seal joints.

Due to the large size of the dump assemblies, mechanical separation of the barrels and the pass-through and water union from the rest of the assembly is desirable and should be engineered to be accomplished before moving to the remote repair room. 


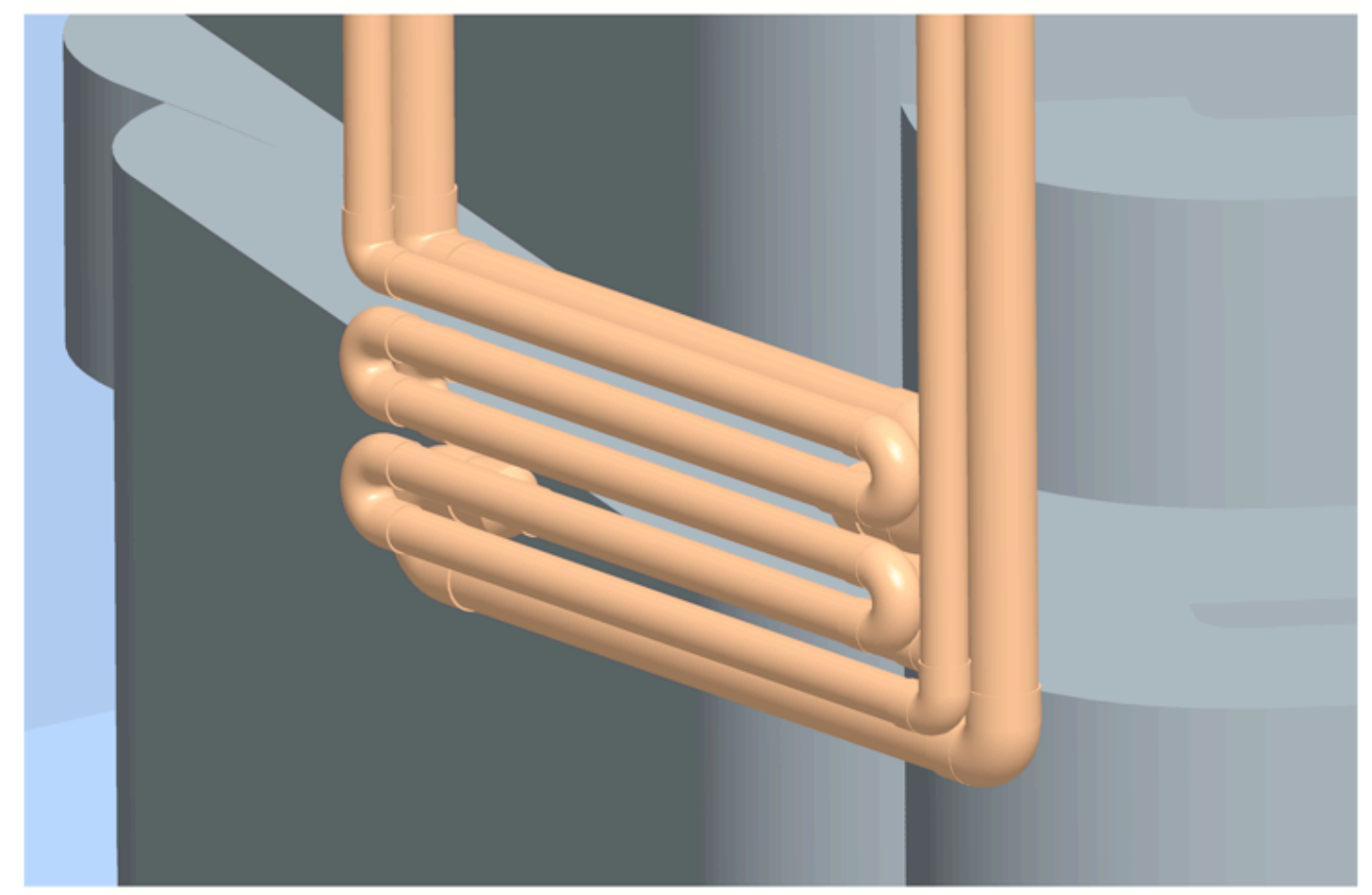

Figure 12. Stationary beam dumps to one side of the dipole magnet.

\section{Summary}

The RIA fragmentation line beam dumps are designed to absorb heavy ion beams up to $300 \mathrm{~kW}$. Due to the high rate of energy deposition in materials of the dump, the beam is allowed to deposit a fraction of its energy in a thin window layer of aluminum alloy before depositing the bulk of its energy in a layer of water. To further reduce the volumetric energy deposition rate in the dump, the dump is designed as a rotating barrel which results in spreading the energy deposition around the perimeter of the barrel. Material and water temperatures are below $100{ }^{\circ} \mathrm{C}$ and thermal stresses are below $5 \mathrm{ksi}$.

Mechanical design of the dump includes an electric motor to rotate the barrel, a rotating vacuum/air shaft seal, and a bellows arrangement that allows remote horizontal movement.

The dumps are designed to allow continuous operation of the dump for at least 10 weeks for the range of expected RIA beam types. 


\section{References}

[1] B. Sherrill, private communication, Michigan State University, Video Conference, 20 May 2004.

[2] B. Sherrill, private communication, Michigan State University, 28 February 2005.

[3] J. Boles, private communication.

[4] S. Reyes, private communication.

[5] A. B. Shapiro,"Topaz3d-A Three-dimensional finite element heat transfer code," LLNL, UCID-20484, 1985.

[6] J. A. Hallquist,’Dyna3d User's Manual,’ LLNL, UCID-19592, May 1989. 